\title{
One of the better models of European cooperation
}

\section{Heldelberg}

LenNart Philipson, an imposing Swede, is particularly proud of 'The Operon', the new 320-seat auditorium at the European Molecular Biology Laboratory (EMBL). It symbolizes his drive, as director general of EMBL since 1982, to fulfil one of the original aims of the 15-year-old laboratory - that it should be a European centre for teaching and training in molecular biology, particularly for the benefit of the smaller countries that help pay the cost.

Training, however, was only one of the main roles foreseen for EMBL by those who argued 20 years ago for its foundation. They also claimed it would act as a meeting-place for senior European molecular biologists (as Cold Spring Harbor does for US biologists and CERN for European particle physicists), a provider of specialized facilities that would be beyond the means of most European countries (again like CERN), and a focus for molecular biology that could help to disseminate the techniques throughout Europe. Critics at the time argued that specialized facilities and large laboratories would funnel molecular biology and its practitioners into an elitist group of little influence on the development of the science in Europe.

With its training role to the foremost, EMBL now hosts annually a dozen practical training courses, most of them run by its own staff, and takes on about ten predoctoral students, whose quality is said to be exceptional. They take their places alongside the 120 or so postdocs who are present at any time, in a laboratory that is demonstrably European to judge by the mix of nationalities of the scientific staff.

But Philipson argues that the training functions of EMBL are much more extensive. With almost all the scientists employed on short- or medium-term contracts, there is no elitist group. Rather, youngish scientists are given an opportunity to make their scientific mark during their most productive years, before dispersing, often to their country of origin, as trained leaders with a European attitude.

The other side of that coin is less bright: with such a turnover of even its betterknown scientific staff, EMBL has some difficulty in building up and sustaining a reputation as an outstanding laboratory, which is what many of its critics think it should be for its size - about 500 people, of whom half are on the laboratory staff and cost — now about $£ 17$ million a year.

At times, this has led one or other of the countries that foot the bill for EMBL to threaten to withdraw. The biggest threat, which ran thoughout 1983 , came from Britain, but ended when a Medical
Research Council review of the laboratory concluded that the British contribution could not have purchased equivalent work of equal quality within Britain.

In fact, no country has withdrawn its support from EMBL, and several more have joined in recent years, although Ireland, Iceland, Portugal and Belgium remain unpersuaded. Of these, only the Belgian contribution would make a noticeable addition to EMBL's budget. If Belgium joined there would be funds to occupy the last remaining space at EMBL - a floor of the brand new wing that houses 'The Operon'.

The same wing already houses the Biocomputing Programme, which recently became the seventh research programme at EMBL and which is, in many ways, just the kind of activity in which a European laboratory should be engaged.

On the one hand, it is an attempt to build a substantial research programme in an area of science - theoretical and computational biology, particularly in relationship to proteins and nucleic acids - in which Europe needs urgently to invest. But that is why it is disconcerting that EMBL is finding serious difficulties in recruiting experienced group leaders.

On the other hand, the Biocomputing Programme includes the EMBL Data Library, which shares with its US and Japanese counterparts the unenviable tasks of feeding emerging DNA sequences (27 million bases so far) into a database and then making it accessible worldwide. The former task is being eased because sequences are increasingly being deposited directly in the library, and the latter by the advent of EMBnet, which will be able to provide access to the current library through national European computer nodes on a DecNet-based network.

Even so, the accelerating rate at which new DNA sequences are being produced means that EMBL will not for long be able to support or even house the data library. Already, the European Commission supports 40 per cent of the activity, but only for two years in the first place, and Philipson is pushing for the foundation of a separate European institute (of bioinformatics, or some such) eventually to handle the library and its functions.

Of EMBL's other research programmes, those known as Gene Expression, Differentiation and, especially, Cell Biology have established reasonable international reputations. The Biological Structures programme, while still struggling to achieve equal footing, is said to be in better shape than it has been.

Meanwhile, the Physical Instrumentation and Biochemical Instrumentation programmes are in danger of disappearing as a matter of policy. Stemming from the original conception of EMBL as molecular biology's counterpart to CERN, the development of instruments has always been one of its missions. Pursued somewhat in a vacuum by the founding director, (now Sir) John Kendrew, instrument development has been much more closely tied to biological programmes by Philipson, who now plans to integrate them completely.

This plan, like other major policy changes at EMBL, is subject to the approval of the laboratory's governing body, the council, which comprises delegates from each contributing country and is advised by a scientific committee. As director general, Philipson is responsible for planning and execution of approved scientific programmes at EMBL, assisted by a committee of staff members.

EMBL also operates two outstations, both with an uncertain future. For that at the Institut Laue Langevin in Grenoble (see page 723) the problem is that neutrons have not turned out to be particularly useful for biologists. Grenoble, however, is the site chosen for construction of ESRF (the European Synchrotron Radiation Facility, see page 723), which will be much more useful, and where EMBL has been asked to provide a biological research support laboratory. If EMBL agrees, the days (or, rather, years) of the second outstation at DESY (the Deutsches Electronen-Synchrotron) in Hamburg will be numbered.

Until a few months ago, Philipson had not expected these problems to be his. But after the pathetic failure of the EMBL council to find a new director (see Nature 337, 397 and 589; 1989), he will stay until 1995 rather than leave in a year's time.

Perhaps for that reason, and tired of being on the defensive about EMBL as well as confident that the laboratory provides much better value for money than Community programmes, Philipson is now strongly promoting the idea of founding more EMBLs, for example, one devoted to plant biology and another to neurobiology.

Peter Newmark

Top men at EMBL (Philipson, left) and EMBO (Tooze)

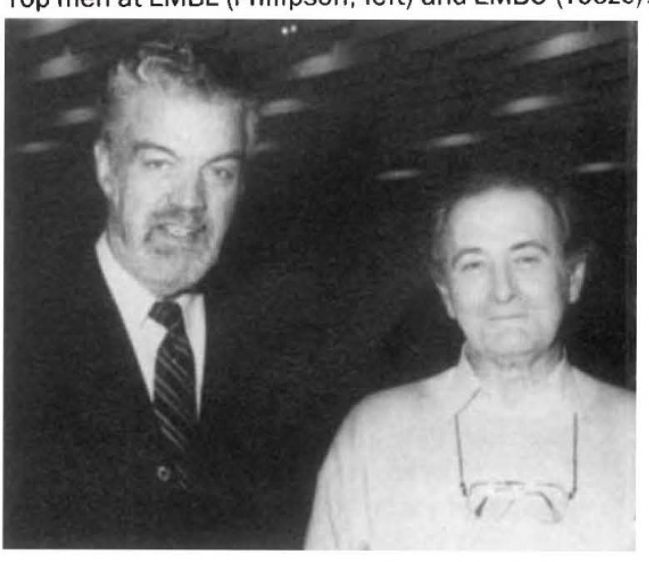

NATURE $\cdot$ VOL $338 \cdot 27$ APRIL 1989 